\title{
ABORDAGEM DA PERSPECTIVA NEOINSTITUCIONAL PARA PROCESSOS DE INTERNACIONALIZAÇÃO DE EMPRESAS DE PAIISES EMERGENTES
}

Data de submissão: 06/09/2017

Aceite: $02 / 08 / 2018$

Luciano Messina Pereira da Silva ${ }^{1}$

Fernando Dias Lopes ${ }^{2}$

\section{RESUMO}

Este ensaio teórico procura associar o conhecimento sobre processos de internacionalização que consideram aspectos econômicos como motivadores e aspectos culturais como barreiras a serem enfrentadas, aos aspectos inerentes à Teoria Institucional. Conceitos inerentes à Teoria Institucional são considerados como residuais por alguns autores ao tratarem de variáveis no nível de país dentro do processo de internacionalização, os quais nem sempre aprofundam o estudo sobre a influência das instituições na internacionalização de uma empresa. Revisou-se a literatura versando sobre processos de internacionalização de empresas, teoria institucional e uma abordagem que assume uma visão baseada em instituições como complementar às visões baseadas na indústria e em recursos como estratégia de internacionalização, constituindo estas três visões o tripé da estratégia, considerando também a influência do ambiente institucional na escolha de uma companhia multinacional pelo modo de entrada em um novo país. Conclui-se que a presença do aspecto institucional está, no mínimo, implícita ao se tratar de questões culturais em processos de internacionalização, e que não pode ser desconsiderada objetivando o sucesso de tais estratégias.

Palavras-chave: Teoria institucional; Processos de internacionalização; Aspectos culturais; Países emergentes.

\footnotetext{
1 Possui graduação em Engenharia Mecânica pela Universidade Federal do Rio Grande do Sul, UFRGS, mestrado em Engenharia de Produção/Sistemas de Produção pela UFRGS e doutorado em Administração/Estudos Organizacionais pela UFRGS. Porto Alegre - RS. Brasil. E-mail: luciano.messina@uol.com.br

2 Possui graduação em Administração de Empresas pela Universidade Federal de Santa Maria, UFSM, mestrado em Administração pela Universidade Federal de Santa Catarina, UFSC e doutorado em Administração pela Universidade Federal do Rio Grande do Sul, UFRGS. Professor Associado II, Universidade Federal do Rio Grande do Sul, UFRGS. Porto Alegre - RS. Brasil E-mail: fdlopes@ea.ufrgs.br
} 


\section{INTRODUÇÃO}

A internacionalização das empresas de países emergentes (como Brasil, China e Índia) e a globalização pela qual passaram a fazer parte são acompanhadas pela interação de diferenças culturais, organizacionais e institucionais, o que torna mais difícil o trabalho dos gestores contemporâneos por exigir a adoção de práticas de administração originadas em culturas e ambientes institucionais diferentes dos seus (CHU; WOOD, 2008; FERREIRA; SERRA, 2008; PENG, 2002; PENG; WANG; JIANG, 2008; PENG; SUN; PINKHAN et al., 2009; ROCHA; ÁVILA, 2015; RODRIGUES; DUARTE, 1997; TANURE; PATRUS, 2011). Desta forma, essas diferenças implicam a ocorrência e necessidade de mudanças na organização, revisando e adaptando sua maneira de trabalhar, afetando as relações interpessoais, grupais, intergrupais e organizacionais, sendo preciso tomar estas diferenças culturais e institucionais como variáveis a serem consideradas antes de competir em mercados globais (FERREIRA; SERRA, 2008; HOFSTEDE, 2001; PENG; WANG; JIANG, 2008; ROCHA; ÁVILA, 2015).

O modo como ocorre o processo de internacionalização de empresas varia entre fusões, aquisições e joint ventures. Em casos de fusões e aquisições, a existência de pontos em comum entre as organizações envolvidas é um fator importante para o sucesso do processo de mudança que irá ocorrer. Quando se trata da formação de joint ventures, as diferenças culturais entre as organizações, assim como diferenças institucionais entre os países de origem de cada organização envolvida, podem influenciar tanto na escolha do modo de entrada em um país estrangeiro (KOGUT, 1983; ROCHA; ÁVILA, 2015), como determinar a forma de construir esta aliança. A necessidade de haver pontos em comum entre as organizações envolvidas não se restringe apenas à Cultura Organizacional, mas também à Cultura Nacional dos países de origem das empresas envolvidas, por sua influência sobre a cultura de suas empresas (HOFSTEDE, 1993, 2001, 2011, 2013; JOHANSON; VAHLNE, 1977, 1990; KOGUT, 1983, 1988, 2004; RODRIGUES; DUARTE, 1997; TANURE; CANÇADO, 2005; TANURE; PATRUS, 2011).

Deve-se considerar a diferença entre o nível de desenvolvimento econômico dos países de origem das organizações envolvidas, e analisar tanto a implantação de práticas organizacionais consideradas globais, mas estranhas à cultura e às instituições de países hospedeiros de suas filiais (FERREIRA; SERRA, 2008; HOFSTEDE, 1993, 2001, 2011, 2013; JOHANSON; VAHLNE, 1977, 1990; KOGUT, 1983, 1988, 2004; PENG, 2002; PENG; WANG; JIANG, 2008; PENG; SUN; PINKHAN et al., 2009; ROCHA; ÁVILA, 2015), como também o impacto nas organizações em que estas práticas são implantadas. A cultura de negócios tem influência efetiva nos resultados das negociações e dos empreendimentos internacionais, e Rodrigues e Duarte (1997) lembram que, por mais que esse assunto já tenha sido discutido ao longo das últimas décadas do século $\mathrm{XX}$, ainda é possível verificar problemas e conflitos não previstos em processos de internacionalização de empresas conduzidos atualmente. Entretanto, creditar às diferenças entre culturas nacionais os problemas encontrados em processos de internacionalização parece ser a resposta mais óbvia.

Dentro do cenário apresentado, considera-se a internacionalização de uma empresa de um país emergente, como o Brasil, associando-se a outra empresa originária de um país desenvolvido; a possibilidade de choques de culturas organizacionais e nacionais existe, o que pode acarretar tanto mudanças na cultura das empresas, como conflitos oriundos das diferenças entre os ambientes institucionais em que estas empresas cresceram. A resistência a essas mudanças será tanto maior quanto maior for a falta de consideração às diferenças culturais existentes (JOHAN- 
SON; VAHLNE, 1977, 1990; RODRIGUES; DUARTE, 1997; TANURE; PATRUS, 2011), sem esquecer das diferenças institucionais existentes (FERREIRA; SERRA, 2008; HOFSTEDE, 1993, 2001, 2011, 2013; HOFSTEDE; MINKOV, 2010; PENG, WANG; JIANG, 2008; ROCHA; ÁVILA, 2015).

Se for considerado que as diferenças culturais e institucionais entre os países de origem das empresas que estão inseridas em um processo de internacionalização contribuem para o maior ou menor sucesso do empreendimento, torna-se necessário compreender sua influência na internacionalização de empresas. Assim, este ensaio teórico tem o objetivo de associar o conhecimento corrente sobre processos de internacionalização (fusões, aquisições e joint ventures), que consideram aspectos econômicos como motivadores e aspectos culturais como barreiras a serem enfrentadas, aos aspectos inerentes à Teoria Institucional, por vezes considerados residuais por autores ao tratarem de variáveis no nível de país dentro do processo de internacionalização, que nem sempre aprofundam o estudo sobre a influência das instituições na internacionalização de uma empresa. A contribuição da Teoria Institucional aos processos de internacionalização seguirá a abordagem de Peng, Wang e Jiang (2008), Peng (2002), Peng, Sun e Pinkhan et al. (2009), que assumem uma visão baseada em instituições como sendo complementar às visões baseadas na indústria e em recursos, constituindo estas três visões o tripé da estratégia, necessário ao se tratar da decisão de internacionalizar-se e de como proceder com esta internacionalização, além da influência do ambiente institucional na escolha de uma companhia multinacional pelo modo de entrada em um novo país (FERREIRA; SERRA, 2008; ROCHA; ÁVILA, 2015).

Este ensaio teórico está dividido em quatro seções, iniciando por esta introdução, seguida por breve revisão teórica, chegando à discussão, às considerações finais, e concluindo com propostas para trabalhos futuros.

\section{REFERENCIAL TEÓRICO}

O referencial teórico desenvolvido está dividido em: processos de internacionalização, aspectos culturais dos processos de internacionalização, aspectos institucionais dos processos de internacionalização e influência da visão baseada em instituições para os processos de internacionalização. Este conjunto de temas permitirá a elaboração de considerações sobre como a teoria neoinstitucional pode contribuir para a compreensão e desenvolvimento de processos de internacionalização de empresas de países emergentes.

\subsection{Processos de Internacionalização}

O Investimento Direto Estrangeiro (IDE) é apenas uma das possibilidades de envolvimento econômico internacional. A busca das empresas pela produção internacional é resultante de falhas de mercado, tornando menos vantajoso para as empresas produzir apenas em seus países de origem para posteriormente venderem no mercado internacional. Desta forma, sem a existência de falhas do mercado internacional, a razão de existir da produção internacional desapareceria (DUNNING, 1988; MACADAR, 2009; PINTO; GASPAR; FERREIRA et al., 2010; STAL; CAMPANÁRIO, 2011).

São três as características que habilitam as companhias multinacionais a explorar de forma única as distorções internacionais de mercado: (1) a habilidade de arbitrar restrições institucionais, (2) a captura de externalidades de informação na condução de negócios internacionais, e (3) a economia de custo obtida pela produção conjunta de fabricação e comercialização - economias de 
escopo. A criação de zonas de livre comércio, com a redução considerável de tarifas e barreiras não tarifárias ao comércio entre nações, tem auxiliado a minimizar estes riscos, resultando em estratégias internacionais (BARNEY; HESTERLY, 2011; CAVUSGIL; GHAURI; AGARWAL, 2002; MACADAR, 2009; PAIVA; HEXSEL, 2005).

Estratégias internacionais são exemplos de estratégias corporativas, especificamente voltadas à expansão de mercado de uma empresa para além dos limites territoriais de seu país de origem, e, como tal, devem atender a dois critérios de valor: (1) devem explorar economias de escopo reais e (2) devem ser custosas de imitar por empresas concorrentes. Economias de escopo podem ser criadas quando as empresas operam múltiplos negócios, e também podem ser criadas quando operam em múltiplos mercados geográficos. Ao adotarem estratégias internacionais, as empresas buscam habilitar-se para explorar oportunidades ambientais ou então neutralizar ameaças ambientais (BARNEY; HESTERLY, 2011; BARTLETT; GHOSHAL, 1989; DUNNING; LUNDAN, 2008). Para que as estratégias internacionais sejam fonte de vantagens competitivas sustentáveis às empresas, estas precisam explorar recursos e capacidades que sejam ao mesmo tempo valiosos, raros e difíceis de imitar, sendo que uma empresa que adota uma estratégia de internacionalização precisa estar organizada de forma a realizar o potencial competitivo pleno de seus recursos e capacidades (BARNEY; HESTERLY, 2011; PAIVA; HEXSEL, 2005).

Dentre os diferentes modos de entrada em um país estrangeiro, destacam-se três em especial, tanto pela complexidade como pela frequência com que são empregados: (1) formar uma joint venture, (2) construir uma nova planta (greenfield) ou (3) adquirir uma empresa já existente. Quanto maior for a diferença cultural entre o país de origem da empresa investidora e o país de entrada desta empresa, e maior for aversão à incerteza dentro de suas práticas organizacionais, maior será a probabilidade de a empresa optar por formar uma joint venture, ou então pela construção de uma nova planta ao invés de uma aquisição (KOGUT; SINGH, 1988). Barreiras de entrada a competidores estrangeiros também podem ser criadas institucionalmente, levantando a influência do ambiente institucional na escolha do modo de entrada em um novo país (FERREIRA; SERRA, 2008; PENG; WANG; JIANG, 2008; ROCHA; ÁVILA, 2015).

Fusões e aquisições apresentaram um crescente papel na economia mundial a partir da 2a Guerra Mundial. Essas transações intensificaram-se em função da redução de barreiras de entrada ao capital externo em vários países, da inserção de países emergentes no mercado global, do fim de alguns monopólios e reservas de mercado, de modernizações institucionais, e de problemas em processos sucessórios em empresas familiares. Entretanto, diferenças culturais entre empresas compradoras e empresas-alvo sempre foram particularmente problemáticas. Empresas compradoras precisam estimar o custo de organização para implementar uma estratégia de fusão ou aquisição, e descontar este custo do valor de uma empresa-alvo. Apesar disso, fusões e aquisições ainda são estratégias usadas como garantia de sobrevivência de empresas, com a finalidade de usar o fluxo de caixa livre para resolver problemas de agência de uma das empresas, e pelo potencial existente de lucros superiores (BARNEY; HESTERLY, 2011; TANURE; CANÇADO, 2005; TANURE; PATRUS, 2011).

A formação de uma joint venture resolve os problemas do parceiro estrangeiro quanto aos fatores culturais, apesar de ter o custo de divisão do controle e da propriedade da empresa (BARNEY; HESTERLY, 2011; KOGUT; SINGH, 1988; KOGUT, 2004). É mais provável haver joint ventures entre empresas grandes do que entre empresas pequenas. Esse tipo de aliança é motivado pela busca de poder de mercado e por sinergias entre as empresas participantes (BARNEY; HESTERLY, 2011). Há impacto positivo na lucratividade das empresas-mãe quando entram em uma joint venture (BARNEY; HESTERLY, 2011; SEIFERT; CHILD; RODRIGUES, 2012). 
Sendo o aspecto econômico um dos impulsionadores do processo de internacionalização de empresas, é importante apresentar a teoria eclética da internacionalização da empresa de John Dunning (1980, 1988, 2000, 2001), também conhecida como Paradigma Eclético, que se propõe a explicar por que uma empresa decide produzir no exterior. Essa proposta considera que determinadas falhas de mercado, tais como custos de informação e de transação, oportunismo dos agentes e especificidades de ativos, conduziriam uma empresa a optar pelo investimento direto no exterior ao invés de atender determinado mercado através de exportações ou licenciamento. Para tanto, a hipótese principal é a de que, para a empresa se comprometer com um IDE, três condições devem ser satisfeitas (DUNNING, 1980):

A empresa deve possuir vantagens de propriedade em comparação com as empresas de outras nacionalidades para atender determinado mercado, geralmente relacionadas a ativos intangíveis;

Para que a primeira condição seja satisfeita, deve ser mais benéfico para a empresa explorar esses ativos diretamente do que vendê-los ou cedê-los na forma de leasing para empresas estrangeiras, devendo valer a pena internalizar as vantagens como parte de suas atividades ao invés de externalizá-las a outras empresas via licenciamento ou outro tipo de contrato;

Além disso, deve ser mais lucrativo para a empresa fazer uso dessas vantagens em associação com algum fator externo ao país doméstico, (por exemplo, recursos naturais, mão de obra de baixo custo, mercado protegido) para que seja mais vantajoso produzir no exterior do que exportar (vantagens de localização).

As três vantagens precisam estar presentes para que uma empresa realize um investimento direto no exterior e gere maior valor agregado do que as empresas domésticas. As vantagens de posse (Ownership), localização (Location) e internalização (Internalization) explicam o escopo e a distribuição geográfica das atividades de empresas multinacionais (PINTO; GASPAR; FERREIRA et al., 2010; STAL; CAMPANÁRIO, 2011). As multinacionais mais bem-sucedidas são aquelas que melhor nutrem e exploram tanto vantagens de posse de recursos como de transações. Quanto maiores forem os custos percebidos de uma falha de transação de mercado, mais as multinacionais irão explorar suas vantagens competitivas via produção internacional ao invés de acordos contratuais com empresas estrangeiras. A imposição de barreiras comerciais tem levado a muitos investimentos em fabricação estrangeira pelas multinacionais. Nesse caso, a redução de custos de transporte e a formação de uniões aduaneiras e blocos econômicos têm levado a grandes especializações regionais de produção pelas multinacionais (DUNNING, 1988). O tipo de vantagens inovadoras geradas pelas multinacionais reflete a dotação de recursos, mercados, cultura, atitudes e estrutura institucional do país de origem. Algumas atividades econômicas são mais inclinadas à internacionalização do que outras (DUNNING, 1988; PINTO; GASPAR; FERREIRA et al., 2010; STAL; CAMPANÁRIO, 2011).

A singularidade da empresa multinacional é sua habilidade de dominar seus recursos geograficamente dispersos em diferentes moedas, e assim tirar vantagem de imperfeições estruturais e transacionais dos mercados de capitais e de câmbio internacionais. À medida que as empresas tornam-se mais voltadas a uma atuação multinacional e assumem uma perspectiva mais global de suas operações, suas vantagens competitivas de propriedade passam a ser menos baseadas na posse exclusiva de certos ativos intangíveis, específicos do país de origem das empresas, e mais em sua habilidade de coordenar e gerenciar com sucesso uma rede de atividades globais (DUNNING, 1988; MACADAR, 2009; PINTO; GASPAR; FERREIRA et al., 2010; STAL; CAMPANÁRIO, 2011), procurando harmonizar as diferenças culturais existentes em uma atuação em escala global. 


\subsection{Aspectos Culturais dos Processos de Internacionalização}

Remetendo ao aspecto cultural do processo de internacionalização, a cultura é tratada como uma construção social que compreende valores compartilhados, crenças e maneiras de se comportar e pensar que são únicas a uma organização específica (CHILD; FAULKNER, 1998). Dentro do estudo da cultura, duas coletividades devem ser consideradas como origem de culturas específicas. Existem as organizações em que os indivíduos trabalham, onde pode ser encontrado o que é conhecido como Cultura Organizacional, e existe a sociedade em que os indivíduos vivem, a qual está relacionada à Cultura Nacional (CHILD; FAULKNER, 1998).

Os fatos, valores e artefatos que os membros de uma organização têm como sendo de existência garantida e, portanto, acreditam que constitua uma realidade em que vivem formam o conceito conhecido por Cultura Organizacional. Pode ser interpretada como a divisão entre membros de uma organização, atuando como uma força unificadora que integra as pessoas em torno de uma tarefa ou operação comum, o que configura uma aliança estratégica; como subculturas de diferentes grupos dentro da organização, que agem como força diferenciadora ou divisora, o que pode ameaçar uma aliança estratégica; e também como mistura fragmentada, paradoxal e ambígua das identidades pessoais, promovida pelo fluxo constante de mudança nas organizações e sociedades, o que pode ser uma fonte de confusão para os membros de uma organização por aliená-los durante a formação de uma aliança estratégica (CHILD; FAULKNER, 1998).

A Cultura Nacional, por sua vez, é adquirida com a educação e está profundamente enraizada em um indivíduo em consequência disto (CHILD; FAULKNER, 1998). Por esse motivo, diferenças culturais tornam-se alvo de interesse e preocupação na ocorrência de alianças estratégicas internacionais. A escolha do modo de entrada de uma empresa em um novo país/mercado é influenciada por diferenças culturais e pela experiência da empresa (KOGUT; SINGH, 1988). Assim, o uso das Dimensões Culturais de Hofstede $(1993,2001,2011,2013)$ é essencial na compreensão de quais países serão mais adequados para a entrada de uma empresa em seu mercado.

Os padrões de investimento de cada país podem ser gerados pelas diferenças nas características setoriais dos investimentos diretos no estrangeiro dentro dos países de origem, sendo a escolha do modo de entrada significativamente influenciada pelas características culturais do país de origem da empresa investidora (KOGUT; SINGH, 1988). Desta forma, as variáveis que influenciam a decisão de qual modo de entrada seguir podem ser divididas em três grupos. Variáveis do nível da indústria refletem barreiras à entrada e padrões de comportamento oligopolista, enquanto as variáveis do nível da empresa estão relacionadas com o conceito de custos de transação, em que a transferência de recursos especializados entre empresas é impedida por falhas de mercado, tornando necessária a expansão da empresa, em alguns casos além-fronteiras, com o objetivo de internalizar esta transferência (COASE, 1937; WILLIAMSON, 1996). Quando a escolha econômica é comparada em nível de países, características culturais provavelmente terão profundas implicações (KOGUT; SINGH, 1988). Não importa quão superior seja a atual corporação multinacional ao substituir as habilidades de comerciantes pela extensão internacional das fronteiras organizacionais, o gerenciamento destas empresas é provavelmente influenciado pela cultura dominante de seu país de origem (KOGUT; SINGH, 1988).

A fronteira da incerteza de operações empresariais no exterior está relacionada com a distância psíquica, definida como a soma dos fatores que interferem no fluxo de informação entre países. A Escola de Uppsala, ou Escola Nórdica, considera que a percepção da distância psíquica se dá em nível coletivo. Quanto maior for a diferença entre o país de origem e o país estrangeiro em termos de desenvolvimento, nível e conteúdo educacional, idioma, cultura, sis- 
tema político, entre outros, maior será o nível de incerteza (HILAL; HEMAIS, 2003; JOHANSON; VAHLNE, 1977; MACADAR, 2009). Esse modelo, todavia, não se aplica à empresas e indústrias que operam em mercados altamente internacionalizados (HILAL; HEMAIS, 2003; JOHANSON; VAHLNE, 1977). Há uma relação entre a Distância Psíquica e as Dimensões Culturais de Hofstede. Tanto a distância psíquica quanto as dimensões culturais trabalham com um nível de agregação muito alto, com resultados obtidos em nível nacional e daí são generalizados, omitindo diferenças regionais, institucionais, setoriais e individuais, especialmente no tocante à acumulação de experiência neste último aspecto, desconsiderando os aspectos subjetivos existentes (HILAL; HEMAIS, 2003).

Considerando-se a cultura como o substrato no qual se firmam as instituições, os aspectos institucionais de uma sociedade, especialmente os referentes às instituições informais, permeiam todas as organizações de uma nação (KOGUT; SINGH, 1988; MEYER; ROWAN, 1992).

\subsection{Aspectos Institucionais dos Processos de Internacionalização}

Quando se fala em variáveis do nível de país, fica implícita a influência das instituições existentes nos processos de internacionalização. Até o fim da década de 1940, as organizações não eram reconhecidas por parte dos sociólogos norte-americanos como um fenômeno social e, por conta disso, não seriam merecedoras de um estudo próprio (TOLBERT; ZUCKER, 1999). Antes da introdução da conceituação institucional, as organizações eram vistas como sistema de produção ou sistema de trocas, e suas estruturas eram vistas como moldadas por sua tecnologia, suas transações, ou pelas relações de poder e dependência que cresciam de tais interdependências (SCOTT, 1987).

O estudo das Instituições dentro da Análise Organizacional iniciou com Selznick, em 1949, que analisou empiricamente a relação entre as organizações e o ambiente institucional, e também com a teorização de Parsons (SCOTT, 1995), que enfatizou o fato de como as instituições integravam uma organização com outra na sociedade, através de regras e contratos universais, e autoridade (THORNTON; OCASIO, 2008).

Instituições são diversamente compreendidas por elementos culturais cognitivos, normativos e regulativos que, junto com atividades e recursos associados, provém estabilidade e significado para a vida social, e refletem relações instrumentais orientadas na busca de objetivos específicos (SCOTT, 2004). Pressões de caráter Coercitivo são exercidas por força de leis estabelecidas e exercício de autoridade, resultando em mudanças mais rápidas visando à conformidade com padrões estabelecidos. Pressões de caráter Normativo são exercidas por força da influência de categorias profissionais em moldar seu ambiente e definir seus rumos, tendo caráter mais voluntário de adoção, sendo que a autoridade, neste caso, é um poder legitimado, normativamente regulamentado. Por último, há pressões de caráter Mimético quando são adotadas características consideradas como garantia de obtenção de sucesso por outras organizações já institucionalizadas, visando ganhar legitimidade para o novo adotante, mesmo que as práticas mimetizadas não sejam suficientes para garantir a eficácia das ações tomadas pela organização (CARVALHO; VIEIRA; LOPES, 1999; DIMAGGIO; POWELL, 1991, 2005; SCOTT, 1987, 1995). A abordagem institucional às organizações enfatiza a dependência ambiental da estrutura organizacional, as dimensões política e cultural envolvidas, e os efeitos dessas dependências na definição da natureza de organizações mais modernas, particularmente a natureza fluida e complexa de organizações criadas em ambientes altamente institucionalizados (SCOTT; MEYER, 1994). 
As instituições implicam historicidade e controle. Formulações iniciais do processo de institucionalização reforçam o papel do hábito e da história em restringir a escolha, ou a força de pressões morais em cimentar a ordem social. Recentemente, passou a ser enfatizada a importância de sistemas simbólicos e mapas mentais que guiam o comportamento (SCOTT, 2008). Entende-se a institucionalização como um processo que ocorre em uma organização ao longo do tempo, refletindo sua própria história distinta, as pessoas que dela fizeram parte, os grupos por ela envolvidos e os interesses por estes abraçados, e a maneira como ela se adapta ao ambiente (SCOTT, 1995). A institucionalização representa um processo condicionado pela lógica de conformidade às normas socialmente aceitas, bem como pela incorporação de um sistema de conhecimento construído ao longo da interação social. Em busca de legitimação e aceitação social, as organizações procuram conformar suas ações e estruturas aos valores ambientais e aos conceitos considerados socialmente aceitos (MACHADO-DA-SILVA et al., 2003). Zucker (1983) lembra que o processo de institucionalização está enraizado na conformidade, não em uma conformidade gerada por sanções positivas ou negativas, ou resultante de um conjunto hermético de conhecimentos advindos deste processo, mas sim uma conformidade enraizada em aspectos garantidos da vida cotidiana. A institucionalização opera para produzir entendimentos comuns sobre o que é apropriado e sobre o que é comportamento significativo (SCOTT, 1987; ZUCKER, 1983).

Tem-se uma consequente homogeneidade de estruturas e ações que podem ser melhor compreendidas pelo princípio institucional do isomorfismo (CARVALHO; VIEIRA; LOPES, 1999; DIMAGGIO; POWELL, 2005). A essência dos argumentos institucionais está fundamentalmente preocupada com a estabilidade social, e chama a atenção para um "conjunto particular de processos sociais reprodutivos", com a conotação de "projetos estáveis para sequências de atividades repetidas" (SCOTT, 2008, p. 428). Essa tendência à estabilidade do sistema social exerce uma influência no campo da estratégia, mais especificamente em estratégias corporativas, dentro das quais encontram-se as estratégias de internacionalização. 0 crescimento do número de teóricos institucionalistas, desde 2002, que passaram a explicar a mudança organizacional a partir da teoria institucional, trazendo conceitos como o empreendedorismo institucional, a lógica institucional e um conceito ampliado de campo institucional, contribuiu para dar um papel mais dinâmico e menos determinístico à teoria institucional quando se trata de mudanças organizacionais, como aquelas advindas de processos de internacionalização de empresas.

Mike Peng (2002, p. 251) questiona "por que as estratégias de firmas de diferentes países e regiões diferem?". Além das respostas óbvias que envolvem diferenças culturais, e de condições do nível da indústria e da firma, deve-se também levar em conta a influência (considerável) de fontes como o estado e a sociedade ao elaborar e implementar a estratégia de uma empresa. A este conjunto de fatores dá-se o nome de Quadro Institucional (DIMAGGIO; POWELL, 1991). Nenhuma firma é imune ao quadro institucional em que está inserida, e deve haver uma preocupação constante por parte dos pesquisadores sobre este tema em relação à influência das instituições no desenvolvimento e na rotina das firmas, sob que circunstâncias ocorre esta influência, qual é sua extensão e de que forma ela ocorre (PENG, 2002). Quadros institucionais interagem com organizações, sinalizando que escolhas são aceitáveis e podem ser apoiadas. Desta forma, instituições ajudam a reduzir a incerteza para as organizações quando estas precisam realizar suas escolhas (PENG, 2002). 


\subsection{Influência da Visão Baseada em Instituições para os Processos de Internacionalização}

Uma visão da estratégia de expansão internacional baseada em instituições emergiu simultaneamente ao surgimento do Novo Institucionalismo nas Ciências Sociais, com foco estratégico na importância das instituições no meio acadêmico e ressaltando a falta da devida atenção ao contexto institucional de cada país por parte das visões baseadas na indústria e em recursos (PENG; SUN; PINKHAN et al., 2009). A associação da visão baseada em instituições às visões baseadas na indústria e em recursos formaria, então, o tripé da estratégia, dando consistência maior à tomada de decisões nas organizações, especialmente ao entrar em ambientes desconhecidos em processos de internacionalização (PENG, 2002; PENG; WANG; JIANG, 2008; PENG; SUN; PINKHAN et al., 2009). Com a adoção complementar desta visão, a interação entre instituições, organizações e escolhas estratégicas passaria a ser considerada, e a tomada de decisões e a construção da estratégia de expansão iria além da análise do ambiente organizacional, pois "a visão baseada em instituições conecta diretamente o processo de construção da estratégia no nível da firma com ambas as abordagens micro e macro da economia institucional" (PENG; SUN; PINKHAN et al., 2009, p. 73), propiciando maiores chances de sucesso para a iniciativa de expansão internacional de uma empresa.

O uso do termo "visão baseada em instituições" é preferido por não se limitar apenas à visão sociológica ou à visão econômica do institucionalismo, pois considera que ambas são complementares e que o uso deste termo na pesquisa em Administração possibilita aproveitar o que há de melhor nestas duas perspectivas da Teoria Institucional (PENG; SUN; PINKHAN et al., 2009), cobrindo tanto instituições formais como informais, podendo inclusive ser incorporada aos três componentes do Paradigma Eclético (DUNNING; LUNDAN, 2008). Instituições formais e informais moldam a estratégia e o desempenho das firmas, tanto domésticas como estrangeiras, em economias emergentes, e a pesquisa em Negócios Internacionais relacionada à competição em economias emergentes, e seu crescimento no cenário global (PENG; WANG; JIANG, 2008), permite que seja investigado como as instituições influem e têm importância nesta área, contribuindo também para que a visão baseada em instituições da estratégia complemente as visões baseadas na indústria e em recursos na formação do tripé da estratégia. Peng, Wang e Jiang (2008), assim como Peng, Sun, Pinkhan et al. (2009), veem as escolhas estratégicas como a interação dinâmica entre instituições e organizações, da mesma forma que as instituições formais e informais são estruturas compensatórias. Deste modo, quando instituições formais falham, instituições informais passam a atuar para reduzir a incerteza e garantir a legitimidade das ações. Observa-se a predominância de redes informais de relacionamento para a construção de estratégias, e no auxílio à tomada de decisão, em países emergentes como a China, entre os executivos de empresas chinesas, ou na relação entre consumidores e fornecedores industriais (PENG; WANG; JIANG, 2008; PENG; SUN; PINKHAN et al., 2009), em que tais relacionamentos contribuem para o crescimento não só da firma, mas da economia como um todo (PENG; SUN; PINKHAN et al., 2009). Pela visão baseada em instituições, quando uma empresa não pode liderar em custos, diferenciação ou foco, ela ainda pode vencer a competição na arena dos relacionamentos políticos informais (PENG; SUN; PINKHAN et al., 2009).

Uma consideração é geralmente feita relacionando crescimento econômico forte com quadro institucional estável e bem determinado, lembrando, então, o paradoxo do crescimento econômico de países como a China, cuja economia é pouco regulamentada. Conforme Peng, Wang e Jiang (2008), as instituições formais subdesenvolvidas acabam por serem 
substituídas informalmente por redes interpessoais cultivadas pelos gerentes na sociedade, cumprindo o papel que seria das instituições formais, quando estas são fracas ou inexistentes. Esse tipo de arranjo pode ser encontrado em várias economias emergentes, onde há predominância de relacionamentos informais no estabelecimento de relações comerciais, como no Brasil (SEIFERT; CHILD; RODRIGUES, 2012). Entretanto, essa relação interempresas não deve ser entendida como uma uniformidade de comportamento e de estratégias, pois dentro de um mesmo ambiente institucional as várias empresas existentes tendem a parecerem similares, porém diferem devido a peculiaridades de seus quadros institucionais próprios, levando-as a comportarem-se de modos diferentes (PENG; SUN; PINKHAN et al., 2009).

As profundas diferenças referentes ao quadro institucional de economias emergentes (como a do Brasil, da China e da Índia) e economias desenvolvidas (como a norte-americana e de parte dos países europeus) levam à necessidade de mudanças quando empresas pertencentes as determinadas realidades institucionais passam a fazer negócios em uma realidade diferente. Surge a necessidade de ocorrer transições institucionais, mudanças fundamentais e compreensivas introduzidas nas regras formais e informais que afetam as firmas que participam desta arena, muitas vezes em mais de um país participante, pois a relação comercial é um encontro de intenções de comercialização entre países de culturas e quadros institucionais diferentes, e ambos os lados precisam adaptar-se a esta nova realidade (PENG; WANG; JIANG, 2008).

A questão-chave proposta por Peng, Wang e Jiang (2008), válida tanto para empresas domésticas como para empresas estrangeiras em economias emergentes, é saber como proceder quando as regras estão mudando e não são completamente conhecidas. Uma das mudanças tratadas por estes autores envolve leis antidumping como barreiras de entrada em um mercado. Enquanto barreiras tarifárias não são mais toleradas na economia atual, barreiras não tarifárias, como regimes antidumping, tornam-se importantes como meio de proteger a indústria de um país, indicando ter ocorrido uma mudança institucional com este movimento, tornando-se o antidumping uma barreira de entrada, o que resulta em um custo de ser estrangeiro de uma empresa multinacional (JOHANSON; VAHLNE, 2009; ZAHEER, 1995).

As decisões de empresas multinacionais quanto ao modo de entrada em novos mercados são influenciadas pelo ambiente institucional, tanto do país de origem dos investimentos como do país de destino. Nem sempre a escolha do modo de entrada pode ser tomada livremente pela empresa devido a existência de barreiras legais à participação majoritária de capital estrangeiro em indústrias consideradas estratégicas. Neste caso, uma decisão inicial de abertura de subsidiárias integrais pode ser alterada, optando-se por realizar uma joint venture com outra empresa nativa do país hospedeiro (ROCHA; ÁVILA, 2015). Isso impõe a necessidade de considerar, além da distância cultural entre os dois países, a distância institucional - diferenças entre o ambiente institucional do país de origem de uma multinacional e do país hospedeiro, onde deseja expandir seu mercado (KOSTOVA apud ROCHA; ÁVILA, 2015) - entre estes países.

Isso pode dificultar a legitimação de uma multinacional ao estabelecer-se em um país com ambiente institucional muito diferente do existente em seu país de origem. Poderá haver dificuldade em transferir suas práticas organizacionais para uma subsidiária a ser instalada em um país com ambiente institucional muito diferente. Desta forma, é possível considerar que uma maior distância institucional entre os dois países indique a preferência pelo estabelecimento de joint ventures, enquanto que uma menor distância institucional 
pode levar à abertura de subsidiária integral, sendo este um fator decisório quanto ao modo de entrada em um país (ROCHA; ÁVILA, 2015).

Além da distância institucional em si, deve ser considerada a qualidade das instituições, questionando sobre o que é mais importante, se é "a diferença entre os padrões das instituições dos países de origem e destino", ou "o nível de qualidade das instituições do país hospedeiro" (ROCHA; ÁVILA, 2015, p. 249). Ambientes institucionais de baixa qualidade regulatória podem refletir instabilidade política local, o que implicaria em maior dificuldade para atender às exigências regulatórias específicas desses ambientes. A associação com um parceiro local que conheça o ambiente pode minimizar o impacto (ROCHA; ÁVILA, 2015). Multinacionais de países emergentes já estão inseridas em ambientes institucionais de baixa qualidade regulatória (em relação aos países desenvolvidos), e, assim, a distância regulatória não deve afetar diretamente na escolha do modo de entrada em outro país, independente de este possuir um ambiente institucional de alta ou baixa qualidade regulatória (ROCHA; ÁVILA, 2015). Essa análise já não se aplica aos ambientes institucionais normativo e cognitivo.

Em relação ao ambiente institucional cognitivo, ou também chamado cultural-cognitivo, este tem sua distância institucional medida, em geral, com o uso das Dimensões Culturais de Hofstede (ROCHA; ÁVILA, 2015). O mimetismo de empresas bem-sucedidas no mercado estrangeiro a ser explorado revela-se não só como uma pressão institucional neste ambiente, mas também como alternativa à multinacional entrante que deseja obter sucesso neste país (FERREIRA; SERRA, 2008). São incluídos na análise do ambiente institucional normativo a corrupção e a burocracia. Em geral "quanto maior for o nível de corrupção no país hospedeiro, maior será a probabilidade de uma firma investidora preferir modos de entrada com menor participação de capital próprio" (ROCHA; ÁVILA, 2015, p. 253), levando a organização, inclusive, a repensar sua estratégia de expansão em determinados ambientes institucionais.

Pressões institucionais (coercitiva, normativa e mimética) do país hospedeiro do investimento de uma empresa multinacional, combinadas com a estratégia de operações extrafronteiras, determinarão o modo de entrada desta empresa em cada país. É possível separar as estratégias de operações multinacionais em estratégia de busca de mercado e estratégia de busca de recursos estratégicos, conforme fazem Ferreira e Serra (2008). A influência do ambiente institucional levará as empresas a buscar obter legitimidade neste ambiente e, para isto, conforme trazem Ferreira e Serra (2008, p. 15), "as empresas precisam selecionar apropriadamente o ambiente em que irão operar, conformar-se a este ambiente e, eventualmente, manipular o ambiente de maneira que facilite a conformidade da organização".

A busca de legitimidade no mercado selecionado e o modo de entrada escolhido por uma empresa multinacional acabam refletindo o grau de enraizamento da empresa com o país escolhido, diminuindo o custo de ser estrangeiro (JOHANSON; VAHLNE, 2009; ZAHEER, 1995), e a adaptação de seus produtos ao público consumidor do país hospedeiro (FERREIRA; SERRA, 2008). As restrições impostas às multinacionais são reflexos, observados com o auxílio da teoria institucional, dos maiores níveis de complexidade estrutural e ambiental a que estão sujeitas em comparação a empresas locais.

Há uma tendência recente em relação às estratégias adotadas pelas empresas multinacionais de valorizar o aprendizado e o incremento de recursos das empresas, em uma abordagem baseada em conhecimentos e competências, visando não apenas a influência de uma expansão de mercado na decisão pelo modo de entrada em um país (FERREIRA; SERRA, 2008). As empresas não iriam apenas procurar novos mercados para aproveitar sua capacidade já existente e manterem-se competitivas, mas também buscariam aumentar a gama de 
recursos e a capacidade que já possuem, visando acessar ativos intensivos em conhecimento que não possuem dentro de seu repertório de capacidades empresariais, assim como em conhecimento específico de novos mercados onde possa atuar, com o propósito de "aprender com outras empresas e países hospedeiros" (FERREIRA; SERRA, 2008, p. 17). Essa busca por recursos estratégicos apresenta-se de várias formas, mas em geral as empresas procuram novo conhecimento em países mais desenvolvidos, o que traz de volta a questão da escolha do modo de entrada de multinacionais de países emergentes (PENG; WANG; JIANG, 2008; PENG; SUN; PINKHAN et al., 2009; ROCHA; ÁVILA, 2015).

A distância institucional afeta de forma diferente multinacionais que seguem estratégias de busca de mercado das que seguem estratégias de busca de recursos estratégicos. No caso de grandes distâncias institucionais, a estratégia de busca de mercado indicaria que as empresas multinacionais deveriam minimizar o envolvimento de recursos no novo país hospedeiro, optando pela exportação de seus produtos, pelo licenciamento a parceiros locais. Por outro lado, a estratégia de busca de recursos estratégicos indicaria uma maximização do envolvimento de recursos, através de joint ventures ou aquisições, a fim de garantir acesso a novos conhecimentos e ganhar, desta maneira, legitimidade e enraizamento no país estrangeiro (FERREIRA; SERRA, 2008). Essas diferenças entre as estratégias adotadas pelas empresas multinacionais também são refletidas na reação a pressões isomórficas internas do novo ambiente institucional, tendo impacto menor para empresas que adotam estratégia de busca de novos recursos estratégicos, cedendo a estas pressões em sua busca por conformidade e legitimidade, porém impactando mais empresas que seguem estratégia de busca de mercado, que não desejam maior envolvimento com o novo ambiente e não têm intenção em ceder a estas pressões isomórficas (FERREIRA; SERRA, 2008).

As empresas multinacionais podem, também, ser usadas como laboratórios para experimentação e transferência de mudanças institucionais entre fronteiras nacionais, devido ao seu alcance e dependendo de sua influência nos países em que atuam, tendo como exemplo a difusão do modelo organizacional divisionalizado além dos Estados Unidos, ou então a hibridização de modelos organizacionais e institucionais, como o ocorrido com a empresa Lenovo, da China, em que a prática cultural chinesa encontrou espaço mesmo após sua aquisição pela IBM em 2005, adotando práticas de gestão da multinacional entrante dentro do país emergente (DUNNING; LUNDAN, 2008). Isso leva empresas multinacionais que focam na padronização de produtos e serviços, baseando sua estratégia global em um modelo de negócios que visa o lucro proveniente de clientes do topo da pirâmide socioeconômica, a focar-se também na base da pirâmide como fonte de lucro ao competirem em economias emergentes, justamente pelo diferente quadro socioeconômico, cultural e institucional existente (PENG; WANG; JIANG, 2008).

\section{DISCUSSÃO E ANÁLISE}

Quando se trata de questões culturais em processos de internacionalização, a presença do aspecto institucional está, no mínimo, implícita. A figura 1, a seguir, auxilia na compreensão dos vários ambientes em que empresas de diferentes países estão inseridas, uma vez que sumariza os diferentes ambientes em que duas empresas estão inseridas durante o processo de associação entre elas, via processo de internalização. 
Figura 1 - Interação entre duas empresas pertencentes a ambientes (cultural e institucional) diferentes

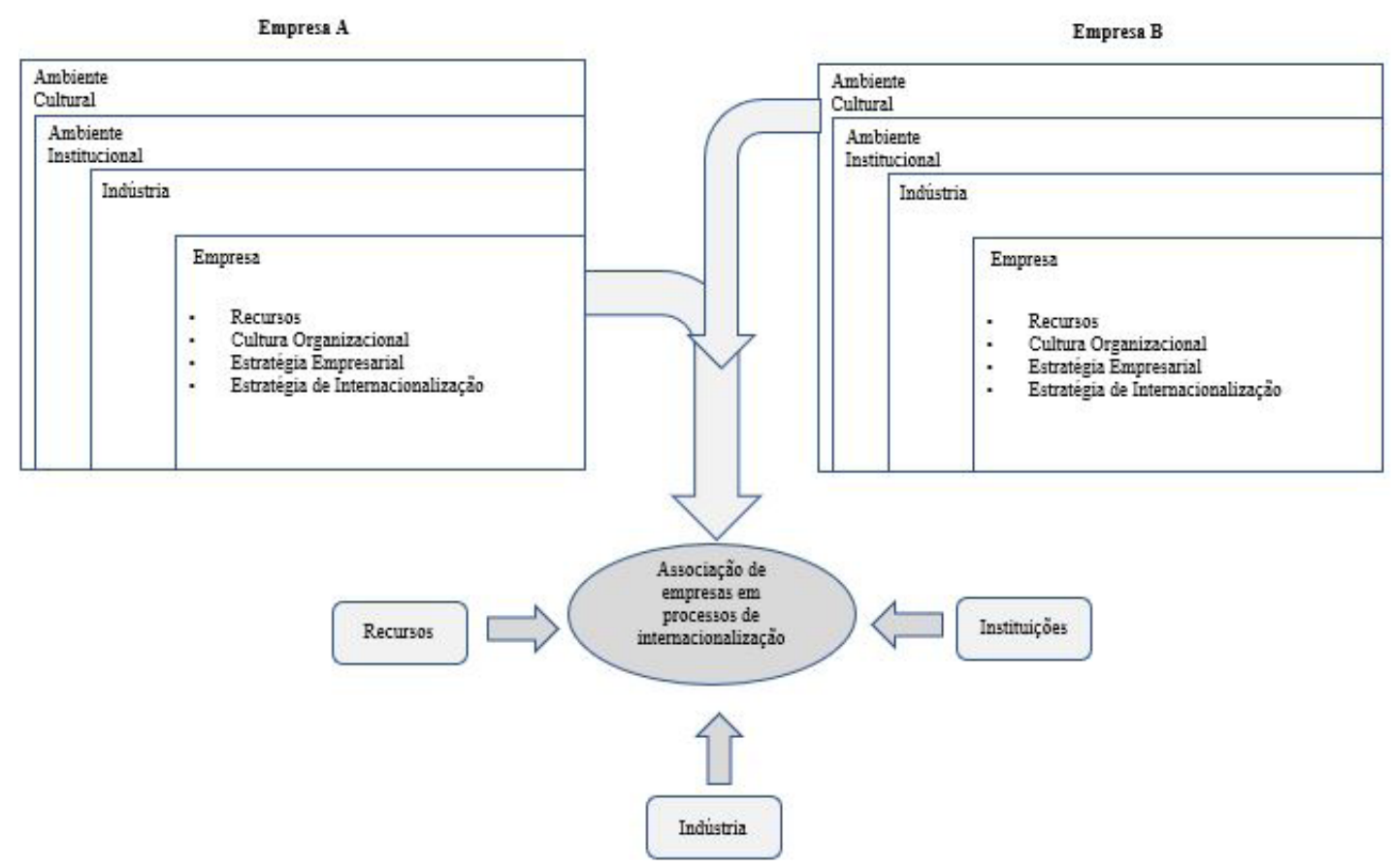

Isso significa que empresas estrangeiras encontrarão diferenças institucionais ao associarem-se aos parceiros potenciais que procuram. Por mais que se fale em um mundo globalizado, deve ser lembrado que instituições buscam a perenidade e a estabilidade do sistema social e que haverá uma troca, uma relação de compromisso entre os parceiros, emergentes e desenvolvidos, se estes quiserem formar alianças comerciais duradouras. Entretanto, esperar que isso ocorra sem sobressaltos é subestimar a força e a importância das instituições dentro dos processos de internacionalização. Pressões institucionais normativas e coercitivas podem levar empresas multinacionais entrantes em um país emergente a sentirem-se compelidas a adaptarem-se à nova realidade se desejarem prosperar no novo mercado, em contrapartida, empresas provenientes de países emergentes (como as brasileiras) podem mimetizar práticas de parceiras de países desenvolvidos ao lançarem-se no mercado internacional.

Os elementos do Paradigma Eclético (ou Paradigma OLI) relacionam-se com a teoria institucional de modo que o reconhecimento de uma visão baseada em instituições, ao se elaborar a estratégia de internacionalização de uma empresa, seja um diferencial nesse processo. Como lançar mão de vantagens de localização, produzindo em países diferentes, sem conhecer as práticas e costumes do mercado de trabalho destes países? Uma firma deve realmente internalizar sua produção, sabendo que um de seus países alvo sobretaxa produtos importados, mas, por outro lado, beneficia estes mesmos produtos se forem produzidos neste país, com mão de obra local? Qual é a segurança que uma firma na qual grande parte de seu valor provém de suas patentes terá ao operar em um país emergente que permite a quebra de patentes, como o Brasil fez com os medicamentos genéricos? Isso apenas para citar um exemplo latino-americano (a China possui muitos outros exemplos). O conhecimento da realidade institucional dos países em que uma multinacional irá operar, assim como as diferenças institucionais a serem enfrentadas, além das diferenças culturais que são usualmente citadas, pode implicar na mudança da decisão sobre o modo de entrada no país. Essa decisão deve levar em conta não somente as distâncias institucionais, mas também sua influ- 
ência na estratégia de internacionalização adotada pela empresa multinacional (FERREIRA; SERRA, 2008).

A globalização, entendida como um movimento econômico autônomo, beneficia principalmente os países economicamente mais fortes por meio de políticas e práticas estabelecidas e institucionalizadas por seus governos. A perda de poder dos estados-nação se dá principalmente com os países e governos economicamente mais fracos, que empregam medidas desproporcionais de atração de capital estrangeiro, como o uso de juros altos, colocando suas economias internas em recessão, mas atraindo investidores externos. Em conjunto com a prática de desvalorização de sua moeda, tornando mais baixos os valores de terra, propriedade, capital e trabalho, esses fatores levam contraditoriamente à prática de apropriação de recursos internos, obrigando empresas locais a competirem sob condições desfavoráveis (RODRIGUES, 2004). Como consequência dessa dependência externa de recursos, tem-se a redução do consumo e a recessão econômica nos países emergentes, estimulando a migração de mão de obra qualificada em massa para países nos quais o investimento em trabalho resulta em compensações financeiras e oportunidades de ascensão. As alternativas que se examinam nos países em desenvolvimento são o aumento das exportações e a internacionalização das empresas (RODRIGUES, 2004). Muitas pequenas e médias empresas não podem mais sobreviver operando apenas em mercados domésticos, ao passo que outras são obrigadas a seguir seus clientes à medida que eles se movem em direção ao mercado estrangeiro, a fim de manter sua posição relativa dentro da cadeia de suprimentos, tendência observada em vários países emergentes, não só no Brasil. Entretanto, pequenas e médias empresas são relativamente deficientes em termos de posse de recursos necessários para dar suporte a um processo de internacionalização (RODRIGUES; CHILD, 2012; SEIFERT; CHILD; RODRIGUES, 2012). Dentro da realidade de escassez de recursos das pequenas e médias empresas, estas seguem uma estratégia de estabelecer relações mais próximas com seus parceiros-alvo no mercado internacional, baseando a relação não apenas em interesses econômicos, mas desenvolvendo uma relação de confiança mais próxima do nível pessoal com os contatos existentes, para que a parceria que possa vir a ser desenvolvida tenha, não apenas um caráter econômico e comercial, mas de relacionamento interpessoal, trazendo confiança mútua ao processo de internacionalização, similar ao que é praticado por dirigentes de empresas chinesas (PENG; WANG; JIANG, 2008). Essas relações são iniciadas pelas pequenas e médias empresas quando estas fazem parte de círculos ou juntas comerciais que se unem em busca de parceiros internacionais, ou através de conexões com instituições que possam intermediar o primeiro encontro entre uma pequena ou média empresa e um possível parceiro internacional (RODRIGUES; CHILD, 2012). No caso das pequenas e médias empresas, os fatores culturais que poderiam dificultar o processo aparentam ter menor influência devido à relação comercial, pessoal e de confiança desenvolvidas entre os parceiros. Os fatores culturais apresentam maior interferência negativa quando trata-se de grandes corporações, possivelmente pelo fato de a relação de confiança entre os parceiros ser baseada mais em relações comerciais do que pessoais (RODRIGUES; CHILD, 2012; SEIFERT; CHILD; RODRIGUES, 2012).

Desta forma, destaca-se a importância em reconhecer a influência de aspectos institucionais em processos de internacionalização, desde a elaboração de estratégias corporativas com a adoção de uma visão baseada em instituições para complementar as visões já existentes, baseadas em recursos e na indústria, abrangendo, assim, dos ambientes micro, meso e macrossocioeconômicos em que as organizações estão inseridas. Apesar de, em um momento inicial, os aspectos institucionais apresentarem barreiras à implementação de estratégias de internacionalização de empresas, especialmente em países emergentes, em que as diferenças culturais e ins- 
titucionais são maiores, seu conhecimento, a compreensão das regras do jogo podem tornar-se uma vantagem competitiva tanto para uma empresa de um país desenvolvido querendo entrar em um país emergente, como para uma empresa de um país emergente querendo lançar-se no mercado internacional, entrando em mercados não apenas emergentes, mas também desenvolvidos, onde irão enfrentar barreiras de entradas, mas que poderão ser contornadas sabendo lidar com as peculiaridades e inserindo-se no sistema social vigente.

\section{CONSIDERAÇÕES FINAIS E PROPOSTAS DE DESENVOLVIMENTOS FUTUROS}

O objetivo deste ensaio teórico é levantar a questão da importância de aspectos institucionais em processos de internacionalização, em especial quando estão envolvidas empresas de países emergentes, como o Brasil, e empresas de países desenvolvidos. Considera-se, com certa frequência, apenas as diferenças culturais como barreiras a serem transpostas para o sucesso em processos de internacionalização de empresas, principalmente sob o ponto de vista do lado emergente. Entretanto, a consideração cultural não está completa sem a devida análise institucional, que pode ser considerada complementar à ela, da mesma forma que é complementar à análise econômica.

O Brasil mudou suas instituições formais para atrair investimentos internacionais a partir dos anos 1990, devido à maior influência e força de instituições externas sobre as nacionais, e sugerindo menor esforço de adaptação institucional de empresas multinacionais que aportaram no país, ou então que expandiram seus investimentos neste. Entretanto, mudanças institucionais formais nem sempre são seguidas de mudanças institucionais informais. A principal questão, como país emergente, está justamente na interação das multinacionais com os parceiros emergentes, cuja influência pode alterar legislações vigentes, mas não pode, da mesma forma, alterar comportamentos legitimados de sua população, população que a qual constituirá seu mercado consumidor e, possivelmente, sua mão de obra.

Partindo do embasamento teórico feito aqui, poderá ser conduzido um estudo empírico para analisar os aspectos institucionais que influenciam a internacionalização de empresas multinacionais atuantes em um país emergente, mais especificamente o Brasil. Para isto, seria necessário escolher empresas estrangeiras que possuem atuação no mercado brasileiro e que já tenham passado pelas mudanças institucionais ocorridas no país nos últimos 30 anos, para que seja possível analisar as dificuldades encontradas no momento inicial, de que forma as empresas lidaram com essas dificuldades, e como se adaptaram tanto à diferenças institucionais quanto à mudanças institucionais ocorridas no Brasil, bem como a reação a estas em sua matriz.

O reverso da moeda também é válido de ser investigado. Que medidas as empresas brasileiras, assim como as de outros países emergentes, precisaram tomar ao entrar em mercados de países desenvolvidos, com legislações protecionistas como as dos Estados Unidos da América, e sem o poder econômico e político de seu país a seu favor? As diferenças institucionais puderam ser contornadas com adaptação, por mimetismo? São questões que ainda estão sendo respondidas, embora nem sempre com clareza suficiente para indicar uma tendência a ser seguida. É preciso analisar a influência do discurso da globalização no movimento de empresas brasileiras que estão procurando inserção internacional e se esta inibe a consideração da influência do Quadro Institucional, tanto naquele em que a empresa está inserida, como no que ela espera inserir-se em seu processo de internacionalização. Além disso, é importante verificar junto à teoria existente, outros aspectos sociais e institucionais que também podem influenciar os processos de internacionalização de empresas. 


\section{REFERÊNCIAS}

BARNEY, J. B.; HESTERLY, W. S. Administração Estratégica e Vantagem Competitiva ? Conceitos e Casos. 3a ed. São Paulo: Prentice Hall do Brasil, 2011.

BARTLETT, C.; GHOSHAL, S. Managing across borders, the transnational solution. Boston: Harvard Business School Press, 1989.

BERGER, P.L.; LUCKMANN, T. A construção social da realidade: tratado de sociologia do conhecimento. 25. ed. Petrópolis: Vozes, 2005.

CARVALHO, C. A. P.; VIEIRA, M. M. F.; LOPES, F. D. Contribuições da perspectiva institucional para análise de organizações. In: Anais do Encontro Nacional da Associação Nacional de Pós-Graduação Pesquisa em Administração, Foz do Iguaçu, PR, Brasil, 1999.

CAVUSGIL, S. T.; GHAURI, P. N.; AGARWAL, M. R. Doing business in emerging markets: Entry and negotiations strategies. Sage Publication Inc, 2002.

CHILD, J.; FAULKNER, D. Strategies of Cooperation: managing alliances, networks, and joint ventures. Oxford University Press, 1998.

CHU, R. A.; WOOD JR, T. Cultura Organizacional Brasileira Pós-globalização: global ou local? Rio de Janeiro: Revista de Administração Pública. v. 42, n. 5, p. 969-994, 2008.

COASE, R. H. The mature off the firm. Economica, v. 4, n. 16, 1937. 386-405 p.

DIMAGGIO, P. J.; POWELL, W. W. Introduction. In: POWELL, W. W.; DIMAGGIO, P. J. (orgs.), The new institutionalism in organizational analysis. Chicago: The University of Chicago Press, 1991. 1-38 p.

DIMAGGIO, P. J.; POWELL, W. W. A gaiola de ferro revisitada: isomorfismo institucional e racionalidade coletiva nos campos organizacionais. Revista de Administração de Empresas, v. 45, n. 2, 2005. 74-89 p.

DUNNING, J. H. Towards an eclectic theory of international production: some empirical tests. Journal of International Business Studies, v. 11, n.1, 1980. 9-31 p.

DUNNING, J. H. The eclectic paradigm of international production: a restatement and some possible extensions. Journal of International Business Studies, v. 19, n. 1, 1988. 1-31 p.

DUNNING, J. H. The Eclectic Paradigm as an Envelope for Economic and Business Theories of MNE Activity. International Business Review, v. 9, n.1, 2000. 163-190 p.

DUNNING, J. H. The Eclectic (OLI) Paradigm of International Production: Past, Present and Future. Int. Journal of the Economics of Business, vol. 8, n. 2, 2001, 173-190 p. 
DUNNING, J. H.; LUNDAN, S. M. Institutions and the OLI Paradigm of Multinational Enterprise. Asia Pacific Journal Of Management, v. 25, n. 4, p. 573-593, 2008.

FERREIRA, M. P.; SERRA, F. A. R. Foreign Entry Modes Under Institutional Pressures: The Impact of Strategic Resource Seeking and Market Seeking Strategies. Revista de Ciências da Administração, v. 10, n. 22, 2008. 11-29 p.

HILAL, A.; HEMAIS, C. A. O Processo de Internacionalização na Ótica da Escola Nórdica: Evidências Empíricas em Empresas Brasileiras. Rio de Janeiro: RAC, v. 7, n. 1, 2003. 109-124 p.

HOFSTEDE, G. Cultural Constraints in Management Theories. Academy of Management Executive, v. 7, n. 1, 1993. 81-94 p.

HOFSTEDE, G. Culture's consequences: comparing values, behaviors, institutions, and organizations across nations. $2^{\text {nd }} e d$. Thousand Oaks, CA: Sage, 2001.

HOFSTEDE, G. Dimensionalizing Cultures: The Hofstede Model in Context. Online Readings in Psychology and Culture, Unite 2. 2011. Disponível em: <http://dx.doi.org/10.9707/23070919.1014>. Acesso em: 04 abr. 2014.

HOFSTEDE, G. Replicating and Extending Cross-National Value Studies: Rewards and Pitfalls - An Example from Middle East Studies. Academy of International Business Insights, v. 13, n. 2, p. 5-7, 2013.

HOFSTEDE, G. J.; MINKOV, M. Cultures and organizations: Software of the mind. $3^{\text {rd }}$ ed. New York, NY: McGraw-Hill, 2010.

JOHANSON, J.; VAHLNE, J. The internationalization process of the firm: a model of knowledge development and increasing market commitment. Journal of International Business Studies, v. 8, n.1, 1977. 23-32 p.

JOHANSON, J.; VAHLNE, J. The mechanisms of internationalization. International Marketing Review, v. 7, n. 4, 1990. 11-24 p.

JOHANSON, J.; VAHLNE, J. The Uppsala internationalization process model revisited: From liability of foreignness to liability of outsidership. Journal of International Business Studies, v. 40, n.9, 2009. 1411-1431 p.

KOGUT, B. Foreign direct investment as a sequential process, Selected conference paper In: KINDLEBERGER, C.; AUDRETSCH, D. (Eds.) The multinational corporation in the 1980's, Cambridge: MIT Press, 1983.

KOGUT, B. Joint ventures: Theoretical and empirical perspectives. Strategic Management Journal, v. 9, n.4, 1988. 319-332 p.

KOGUT, B. Joint Ventures and the option to expand and acquire. Oxford University Press, 2004. 
KOGUT, B.; SINGH, H. The effect of national culture on the choice of entry mode. Journal of International Business Studies, v. 19, n.3, 1988. 411-432 p.

MACADAR, B. M. B. A internacionalização de grandes empresas brasileiras e as experiências do Grupo Gerdau e da Marcopolo. Ensaios FEE, v. 30, n.1, 2009. 7-34 p.

MACHADO-DA-SILVA, C. et al. Institucionalização da mudança na sociedade brasileira: o papel do formalismo. In: VIEIRA, M. M. F.; CARVALHO, C. A. (Orgs.). Organizações, instituições e poder no Brasil. Rio de Janeiro: Ed. FGV, 2003. 179-202 p.

MEYER, J. W.; ROWAN, B. Institutionalized organizations: formal structures as myth and ceremony. In: MEYER, J. W.; SCOTT, W. R. Organizational environments: ritual and rationality. Updated Edition. London: Sage, 1992.

PAIVA, E. L.; HEXSEL, A. E. Contribuição da Gestão de Operações para a Internacionalização de Empresas. Rio de Janeiro: RAC, v. 9, n. 4, 2005. 73-95 p.

PENG, M. W. Towards an Institution-based View of Business Strategy. Asia Pacific Journal Of Management, v. 19, n. 2-3, p. 251-267, 2002.

PENG, M. W.; WANG, D. Y.; JIANG, Y. An Institution-based View of International business strategy: a Focus on Emerging Economies. Journal of International Business Studies, v. 39, n. 5, p. 920-936, 2008.

PENG, M. W.; SUN, S. L.; PINKHAN, B.; CHEN, H. The Institution-based View as a Third Leg for a Strategy Tripod. Academy of Management, v. 23, n. 3, p. 63-81, 2009.

PINTO, C. F.; GASPAR, L. F.; FERREIRA, M. P.; SERRA, F. A. R. A influência de John Dunning na investigação em estratégia e negócios internacionais: Um estudo bibliométrico no Strategic Management Journal. Working Paper, v. n. 53, p. 1-35, 2010.

ROCHA, A.; ÁVILA, H. A. Teoria Institucional e Modos de Entrada de Multinacionais de Países Emergentes. São Paulo: RAE, v. 55, n. 3, 2015. 246-257 p.

RODRIGUES, S. B. Desafios da Administração no Século XXI. RAE [? Edição Especial Minas Gerais, v. 44, n. SPE, p. 108-110, 2004.

RODRIGUES, S. B.; CHILD, J. Building Social Capital for Internationalization. Rio de Janeiro: RAC, v. 16, n.1, 2012. 23-38 p.

RODRIGUES, S. B.; DUARTE, R. G. Diversidade Cultural no Ambiente de Negócios Internacionais. Ensaios de Administração. Belo Horizonte: Centro de Pós-Graduação e Pesquisas em Administração da Universidade Federal de Minas Gerais, 1997.

SCOTT, W. R. The Adolescence of Institutional Theory. Administrative Science Quarterly, 1987. 
SCOTT, W. R. Institutions and organizations. London: Sage, 1995.

SCOTT, W. R. Institutional Theory: Contributing to a Theoretical Research Program. In: SMITH, K. G.; HITT, M. A. Great Minds in Management: The Process of Theory Development, Oxford University Press, 2004.

SCOTT, W. R. Approaching Adulthood: The Maturing of Institutional Theory. Theory and Society. In: Theorizing Institutions: Current Approaches and Debates, v. 37, n. 5, 2008. 427-442 p.

SCOTT, W. R.; MEYER, J. Institutional environments and organizations: structural complexity and individualism. London: Sage, 1994.

SEIFERT, R. E.; CHILD, J.; RODRIGUES, S. B. The Role of Interpretation in the Internationalization of Smaller Brazilian Firms. Rio de Janeiro: BAR - Brazilian Administration Review, v. 9, n. 4, 2012. 475-493 p.

STAL, E.; CAMPANÁRIO, M. A. Inovação em Subsidiárias de Empresas Multinacionais: A Aplicação do Paradigma Eclético de Dunning em Países Emergentes. REAd, v. 17, n. 2, p. 560-591, 2011.

TANURE, B.; CANÇADO, V. L. Fusões e Aquisições: Aprendendo com a Experiência Brasileira. RAE, v. 45, n. 2, p. 10-22, 2005.

TANURE, B.; PATRUS, R. Os dois lados da moeda em fusões e aquisições: $\mathbf{O}$ case da F\&A dos bancos ABN AMRO, Real, Sudameris e Santander. Rio de Janeiro: Elsevier, 2011.

THORNTON, P.; OCASIO, W. Institutional logics. In: GREENWOOD, R.; OLIVER, C.; SAHLIN, K.; SUDDABY, R. (orgs) The Sage Handbook of Organizational Institutionalism. London: Sage Publications. 2008. 99-129 p.

TOLBERT, P.S.; ZUCKER, L.G. A Institucionalização da Teoria Institucional. In: CLEGG, S.; HARDY, C.; NORD, W. (Orgs.) CALDAS, M.; FACHIN, R.; FISCHER, T. (Orgs. brasileiros). Handbook de estudos organizacionais: modelos de análise e novas questões em estudos organizacionais. São Paulo: Atlas, v. 1, 1999. 195-219 p.

WILLIAMSON, O. E. Economics and organization: a primer. California Management Review, v. 38, n. 2, 1996. 131-146 p.

ZAHEER, S. The liability of foreignness. Academy of Management Journal, v. 38, n. 2, 1995. 341$363 \mathrm{p}$.

ZUCKER, L. G. Organizations as Institutions. In: BACHARACH, S. B. Research in the Sociology of Organizations, v. 2, n. 1, p. 1-47, 1983. 